\section{MANCHESTER 1824}

The University of Manchester

\title{
To Pump Or Not To Pump?
}

\section{Rahm M, Mezher S, Chandrasekaran S.}

\section{Department of Paediatrics, Macclesfield District General Hospital}

\section{Introduction}

- Diabetes is a common chronic condition affecting both children and adults. There are severa types of diabetes however this poster will only be focussing on Type 1.

- Type 1 diabetes in the most common type in children. It is due to the body's inability to produce insulin, a hormone necessary for the control of blood sugar levels.

- In 2014 diabetes UK found that 35,000 young adults and children had diabetes ${ }^{1}$.

- Insulin pumps are used in the management of type 1 diabetes in children at Macclesfield District General Hospital (MDGH). Insulin pumps are administered under strict guidelines of which patients have to fulfil in order to be granted an NHS funded pump. The pumps cost $£ 2000-£ 3000^{2}$

- We wanted to check the efficacy of the insulin pumps against non pump methods such as multiple daily injections at MDGH.

\section{Methods}

- Review of National Diabetes Audits at MDGH on the number of admissions, type of admissions and insulin administration methods were collected from the years $2012-2015$

- The types of admissions were grouped into preventable and non preventable. See figure 1.

- Non insulin pump methods were grouped as non pump.

- Average $\mathrm{HbA} 1 \mathrm{C}$ levels were collected using Accucheck.

- 85 patients between ages of 4-18 were identified, 50 of which were on a pump.

- The number of preventable admissions and average $\mathrm{HbA} 1 \mathrm{c}$ levels of the pump group were then compared to the results of the non pump group.

- Exclusions: Any patients who were no longer at MDGH or were out of range for the area were excluded. Patients who had both their $\mathrm{HbA} 1 \mathrm{c}$ levels and admissions records missing were excluded.

\section{Preventable}

- Hypoglycaemia

- Hyperglycaemia

- Ketosis without acidosis

- Diabetic ketoacidosis

- Stabilisation more than one time

- Accidental overdose

Admission for a surgical procedure

- Infection

- Other causes

Non- Celiac

- Funny do

- Polyuria and polydipsia

- Newly diagnosed diabetic

- Asthma

- Stabilisation on one occasion

Figure 1: The conditions included under preventable and nonpreventable admissions.

\section{Results}

- Three patients were excluded when comparing $\mathrm{HbA} 1 \mathrm{c}$ levels as no data on $\mathrm{HbA} 1 \mathrm{c}$ could be found in the notes.

- The pump group had lower HbA1c levels, $82.01 \pm 5.609 \mathrm{mmol} / \mathrm{mol}$, compared to non pump, $99.70 \pm 11.299 \mathrm{mmol} / \mathrm{mol}$. P value for average $\mathrm{HbA} 1 \mathrm{C}$ was $<0.167$. See table 1 .

- Total Preventable Admissions were on average lower in the pump group than non pump group, $36 \%$ and $51 \%$ respectively. $P$ value for Total Preventable Admissions was $<0.463$. See Table 1.

- These results were not statistically significant.

Table 1: The differences in the mean for Average HbA1c and Total Preventable admissions between pump vs non pump.

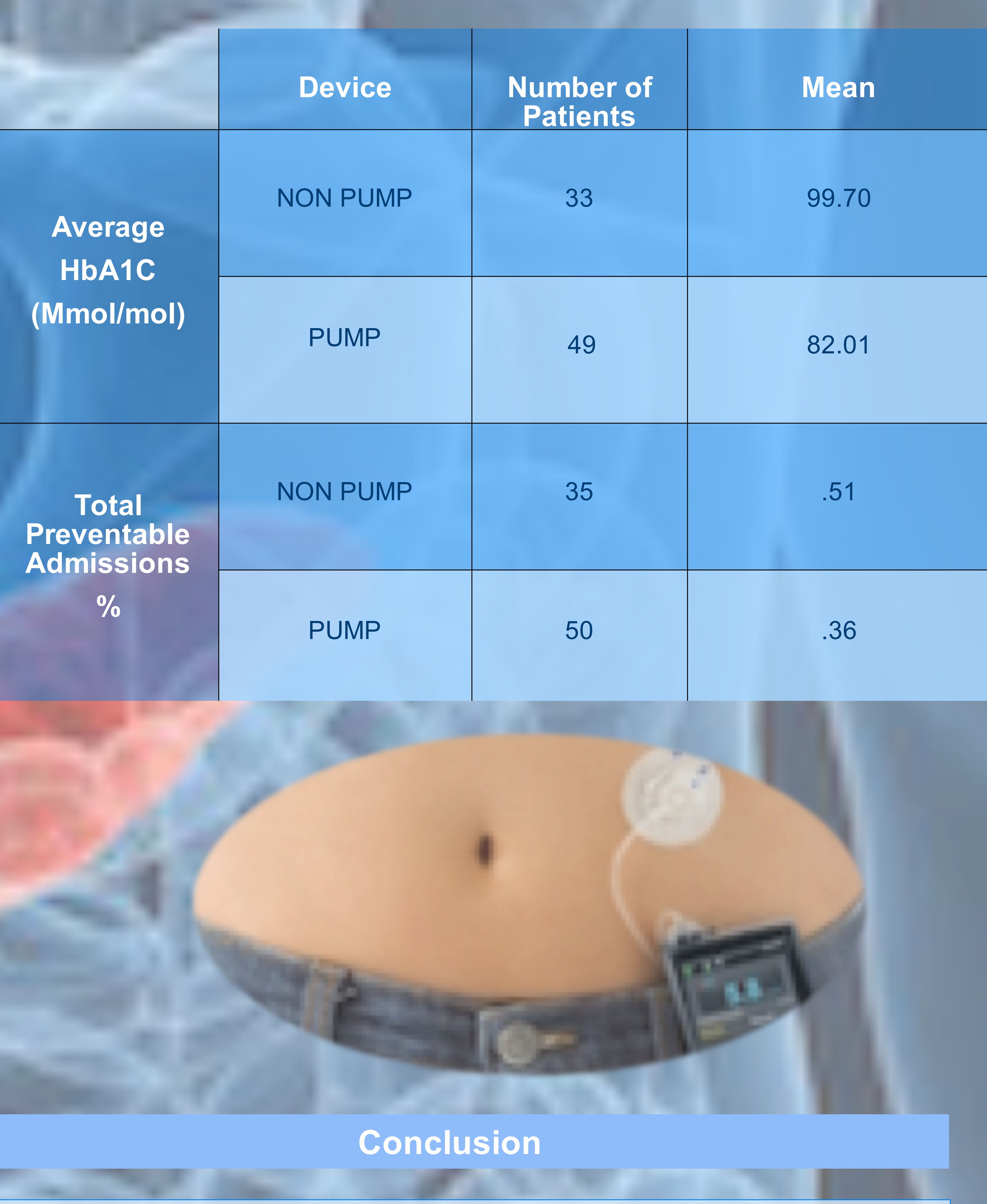

- No significant difference in Average HbA1c levels or Total Preventable Admissions was found in this study. However, with the increased patient quality of life, pump therapy is still essential.

- To reduce admissions and improve glycaemic control, comprehensive education, with the help of a multidisciplinary team is needed.

- Prospective studies testing insulin pump efficacy are warranted.

\section{References}

1) HSCIC: National Diabetes Audit 2011/12: Report 1: Care Processes and Treatment Targets. http://www.hscic.gov.uk/searchcatalogue?productid=13129\&q=\%22National+diabetes+audit $\% 22 \&$ sort=R elevance\&size $=10 \&$ page $=1 \#$ top $(29,576$ registered with GP practices within the NDA survey.

2) $\{$ Accessed 09/11/2015\} http://www.diabetes.co.uk 